\title{
Microscopic Uses of Nanogold ${ }^{\circledR}$
}

\author{
James F. Hainfeld, Richard D. Powell, and Frederic R. Furuya
}

\section{INTRODUCTION}

Gold has been used for immunocytochemistry since 1971 when Faulk and Taylor discovered adsorption of antibodies to colloidal gold. ${ }^{5}$ It is an ideal label for electron microscopy (EM) due to its high atomic number, which scatters electrons efficiently, and the fact that preparative methods have been developed to make uniform particles in the appropriate size range of 5 to $30 \mathrm{~nm} .{ }^{16}$ Use in light microscopy (LM) generally requires silver enhancement (autometallography; AMG) of these small gold particles.

Significant advances in this field since that time have included a better understanding of the conditions for best antibody adsorption, more regular gold size production, adsorption of other useful molecules, like protein A, ${ }^{28}$ and advances in silver enhancement. ${ }^{4,8,18}$ Many studies have also been accomplished showing the usefulness of these techniques to cell biology and biomedical research.

A further advance in this field was the development of Nanogold ${ }^{\circledR}$, a $1.4 \mathrm{~nm}$ gold cluster. ${ }^{12}$ A significant difference from colloidal gold is that Nanogold is actually a coordination compound containing a gold core covalently linked to surface organic groups (Figures 6.1 and 6.2). These in turn may be covalently attached to antibodies (Figures 6.3 and 6.4). This approach to immunolabeling has several advantages compared to colloidal gold such as vastly better penetration into tissues, generally greater sensitivity, and higher density of labeling. 31,32

Since Nanogold is covalently coupled to antibodies, it may also be directly coupled to almost any protein, peptide, carbohydrate, or molecule of interest, including molecules which do not adsorb to colloidal gold. This increases the range of probes possible, and expands the applications of gold labeling.

Below are presented some established protocols for use of Nanogold in the LM and EM, and also how to use it as a general labeling reagent. More specifically, this chapter covers:

- General comments.

- Materials and reagents needed.

- Nanogold labeling for LM.

- Nanogold labeling of cells in suspension.

- Nanogold labeling for transmission EM (TEM) pre-embedding.

- Nanogold labeling for transmission EM postembedding. 
- Double labeling for EM (Nanogold and $10 \mathrm{~nm}$ colloidal gold).

- Using negative stains with Nanogold.

- Nanogold labeling using monomaleimido-Nanogold.

- Labeling Fab' fragments with Nanogold.

- Labeling IgG molecules with Nanogold.

- Labeling other proteins with monomaleimido-Nanogold.

- Nanogold labeling using mono-NHSNanogold.

- Labeling proteins (MW 15000 or greater) with mono-NHS-Nanogold (NHS = N-hydroxysuccinimide).

- Labeling peptides (MW 6000 or less) with mono-NHS-Nanogold.

- Labeling liposomes with dipalmitoylphosphatidylethanolamine (DPPE)Nanogold.

- Forming heavily gold-labeled liposomes and micelles.

- Forming liposomes "spiked" with Nanogold-DPPE.

- Forming very large liposomes ( $>0.5$ $\mu \mathrm{m})$ spiked with Nanogold-DPPE.

- Direct viewing of Nanogold in the EM.

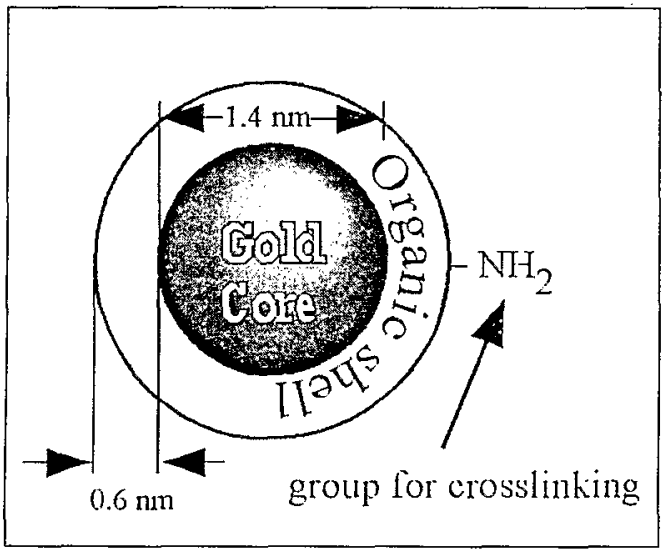

Figure 6.I. Schematic diagram of Nanogold. Shown are rle $1.4 \mathrm{~nm}$ gold core, the $0.6 \mathrm{~nm}$ organic shell, and the monofunctional linking group for covalent artachment co other moleculcs.
Since Nanogold is available commercially, additional useful information, applications, and references are accessible at the manufacturer's web site at www. nanoprobes.com (Nanoprobes, Yaphank, NY, USA).

\section{PROTOCOLS}

\section{General Comments about Using Nanogold}

Nanogold conjugates can be stored in $0.02 \mathrm{~mol} / \mathrm{L}$ sodium phosphate buffer with $150 \mathrm{mmol} / \mathrm{L}$ sodium chloride, or other. buffer solutions usually used with the protein under study. If they are to be stored longer than three days, add $0.1 \%$ bovine serum albumin (BSA) and $0.05 \%$ sodium azide to prevent bacterial contamination and to prevent the protein from adhering to the surfaces of the storage vessel.

Thiol caution: Nanogold particles degrade upon exposure to concentrated

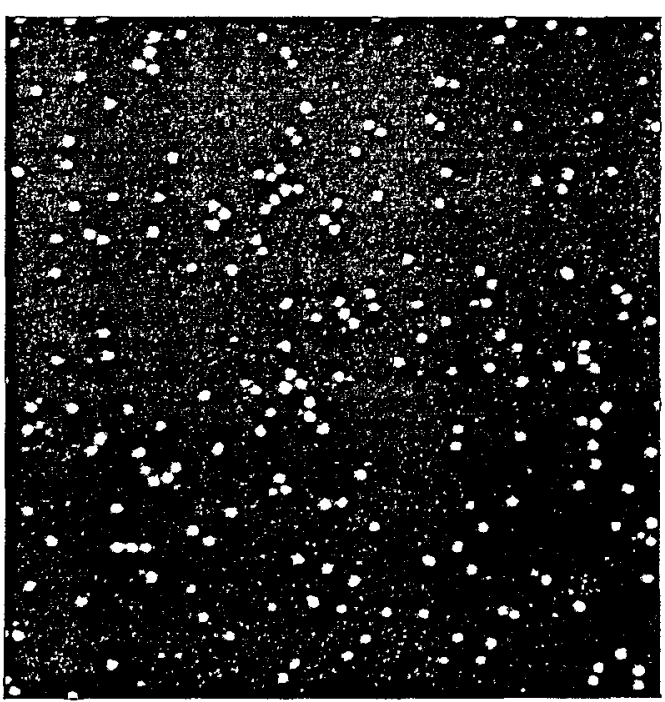

Figure 6.2. Darkfield scanning transmission electron micrograph of Nanogold clusters on a thin carbon film. Each brighe dor is a $1.4 \mathrm{~nm}$ Nanogold particle. Full width $128 \mathrm{~nm}$. (Reproduced with permission from Hainfeld, J.F., 1996. Labcling with Nanogold and undecagold: techniques and results, Sanning Microse. Suppl. 10:309-322.) 
thiols such as $\beta$-mercaptoethanol (BME) or dithiothreitol (DTT). If such reagents must be used, concentrations should be kept below $1 \mathrm{mmol} / \mathrm{L}$ and exposure restricted to 10 min or less, but preferably they should be avoided.

If aldehyde-containing reagents have been used for fixation, it is recommended that these be quenched before labeling. This may be achieved by incubating the specimens for $5 \mathrm{~min}$ in $50 \mathrm{mM}$ glycine solution in phosphate-buffered saline (PBS) ( $\mathrm{pH} 7.4)$. Ammonium chloride (50 $\mathrm{mM}$ ) or sodium borohydride (0.5-1 $\mathrm{mg} / \mathrm{mL}$ ) in PBS may be used instead of glycine.

Silver enhancement: LI Silver (Nanoprobes) is a procedure recommended by the authors for enhancing Nanogold for LM observation; it is light insensitive enough for this application. HQ Silver (Nanoprobes) is recommended for EM, but must be used under safelight or low light conditions. Alternative developers include those described by Danscher and Norgaard, ${ }^{4}$ Hacker et al.,8 Burry et al., 3 and others available commercially. Most recently, light-insensitive gold saltbased AMG developers have been introduced (see Chapter 3).

\section{Materials and Reagents}

- PBS Buffer: $20 \mathrm{mmol} / \mathrm{L}$ phosphate with $150 \mathrm{mmol} / \mathrm{L} \mathrm{NaCl}, \mathrm{pH} 7.4$.

- PBS-BSA Buffer: $20 \mathrm{mmol} / \mathrm{L}$ phosphate with $150 \mathrm{mmol} / \mathrm{L} \mathrm{NaCl}, \mathrm{pH} 7.4$, $0.5 \% \mathrm{BSA}, 0.1 \%$ gelatin (high purity).

- Optional, may reduce background: $0.5 \mathrm{~mol} / \mathrm{L} \mathrm{NaCl}, 0.05 \%$ Tween $^{\circledR} 20$.

- Buffer 1: $20 \mathrm{mmol} / \mathrm{L}$ phosphate, 150 $\mathrm{mmol} / \mathrm{L} \mathrm{NaCl}, \mathrm{pH} 7.4,4 \%$ BSA, 2 $\mathrm{mmol} / \mathrm{L}$ sodium azide $\left(\mathrm{NaN}_{3}\right)$.

- PBS++: PBS containing 1\% BSA, $0.1 \%$ sodium azide, and $1 \%$ normal goat serum.

- PBS*: PBS containing $1 \%$ non-fat dry milk and $1 \mathrm{mg} / \mathrm{mL}$ bovine $\mathrm{IgG}$.

- Nanogold ${ }^{\circledR}$ goat anti-mouse Fab' and other Nanogold-Fab' or Nanogold-IgG secondary antibodies (Nanoprobes).

- LI Silver ${ }^{\mathrm{TM}}$ : Silver developer for LM, or

- HQ Silver ${ }^{\mathrm{TM}}$ : Silver developer for EM, or

- Silver acetate AMG developer: ${ }^{8}$ see Chapter 4.

- Monomaleimido-Nanogold (Nanoprobes).

- Mono-NHS-Nanogold (Nanoprobes).

- NanoVan (negative stain from Nanoprobes).
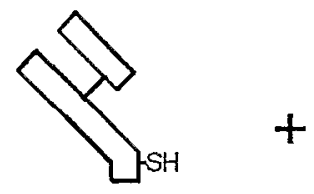

$\mathrm{Fab}^{\prime}$

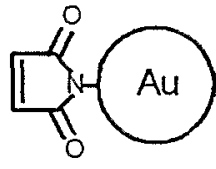

Monomaleimido

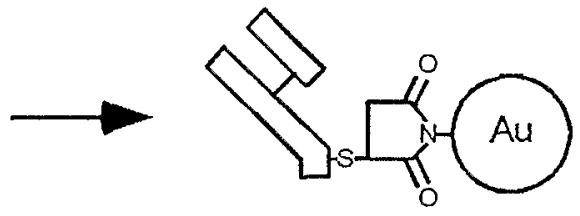

Fab'-Au 
- Centricon ${ }^{\circledR}$ centrifuge filtration products (Amicon ${ }^{\circledR}$, subsidiary of Millipore, Bedford, MA, USA).

- Amicon gel filtration media (Amicon).

- Some Amersham Pharmacia Biotech products (Amersham Pharmacia Biotech, Piscataway, NJ, USA).

- Some Bio-Rad products (Bio-Rad, Hercules, CA, USA).

\section{Protocol 1. Nanogold Labeling for LM}

Features labeled with Nanogold will be stained black in the LM upon AMG enhancement. Different development times should be tried to determine which is best for your experiment. The procedure for immunolabeling is similar to that for EM; one suitable procedure adapted for cytology is given below. Optimum protocols for immunohistopathology are given in Chapter 4.

Samples must be rinsed with deionized or better redistilled water before silver enhancement. This is because the reagent contains silver ions in solution, which react to form a precipitate with chloride, phosphate, and other anions that are components of buffer solutions.

\section{Staining Procedure}

1. Spin cells onto slides using Cytospin ${ }^{\circledR}$ (Shandon, Pittsburgh, PA, USA), or use paraffin section.

2. Incubate with $1 \%$ solution of PBS-BSA for $10 \mathrm{~min}$ to block nonspecific protein binding sites.

3. Incubate with primary antibody, diluted at usual working concentration in PBS-BSA (1 h or usual time).

4. Rinse with PBS-BSA (3 times for $2 \mathrm{~min}$ ).

5. Incubate with Nanogold reagent (c.g., Nanogold-labeled secondary layer antibodies, or Fab' fragments) diluted $1 / 40$ to $1 / 200$ in PBS-BSA with $1 \%$ normal serum from the same species as the Nanogold reagent, for $1 \mathrm{~h}$ at room temperature.

6. Rinse with PBS (3 times for $5 \mathrm{~min}$ ).

7. Postfix with $1 \%$ glutardialdehyde in $\mathrm{PBS}$ at room temperature (3 $\mathrm{min})$.

8. Rinse with deionized water (3 times for 1 min).

9. Develop specimen with freshly mixed developer for 5 to $20 \mathrm{~min}$, or as directed in the instructions for the silver reagent. More or less time can be used to control intensity of signal. A series of different development times may be used, to find the optimum enhancement for your experiment. Generally, a shorter antibody incubation time will require a longer silver development time. Development with light-insensitive silver enhancers may be monitored under the LM (see Chapters 2 and 3).

10. Rinse with deionized water ( 2 times for 5 min).

11. The specimen may now be counterstained if desired before examination, with usual reagents.

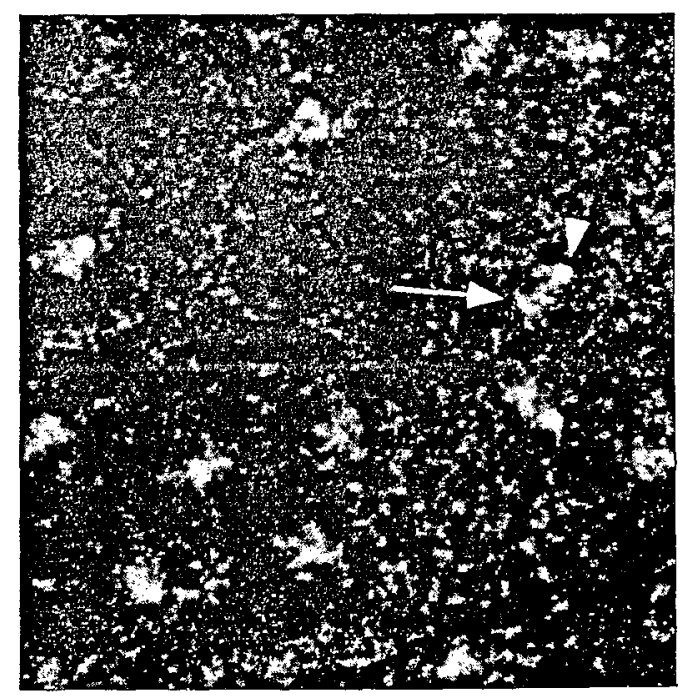

Figure 6.4. Darkfield scanning transmission electron micrograph of Nanogold-Fab' fragments. Bright dors are che Nanogold clusters (arrowhead), and grey masses (arrow) are the liab' fragments. Full width $128 \mathrm{~nm}$. 
Protocol 2. Nanogold Labeling of Cells in Suspension

\section{Staining Procedure}

1. Optional fixing of cells: e.g., with glutardialdehyde $(0.05 \%-1 \%$ for $15 \mathrm{~min})$ in PBS. Do not use Tris buffer for fixation since this contains an amine. After fixation, centrifuge cells (e.g., $1 \mathrm{~mL}$ at $10000000 \mathrm{cells} / \mathrm{mL}$ ) at $300 \times g$ for $5 \mathrm{~min}$, discard supernatant, and resuspend in 1 $\mathrm{mL}$ buffer. Repeat this washing (centrifugation and resuspension) 2 times.

2. Incubate cells with $0.02 \mathrm{~mol} / \mathrm{L}$ glycine in PBS (5 min). Centrifuge, then resuspend cells in PBS-BSA buffer for 5 min.

3. Place 50 to $200 \mu \mathrm{L}$ of cells into Eppendorf $\left.^{(}\right)$tube and add 5 to $10 \mu \mathrm{L}$ of primary antibody (or antiserum). Incubate 30 min with occasional shaking (do not create bubbles which will denature proteins).

4. Wash cells using PBS-BSA as described in step 1 ( 2 times for $5 \mathrm{~min}$ ). Resuspend in $1 \mathrm{~mL}$ Buffer 1 .

5. Dilute Nanogold approximately 50 times in PBS-BSA buffer and add 30 $\mu \mathrm{L}$ to cells. Incubate for $30 \mathrm{~min}$ with occasional shaking.

6. Wash cells in PBS-BSA as described in step 1 ( 2 times for $5 \mathrm{~min}$ ).

7. Fix cells and antibodies using a final concentration of $1 \%$ glutardialdehyde in PBS for $15 \mathrm{~min}$. Then remove fixative by washing with Buffer 1 ( 3 times for $5 \mathrm{~min}$ ).

\section{Protocol 3. Nanogold Labeling for TEM Pre-embedding}

\section{Staining Procedure}

1. Float on a drop of water for 5 to $10 \mathrm{~min}$.

2. Incubate cells with $1 \%$ PBS-BSA. buffer at $\mathrm{pH} 7.4$ for $5 \mathrm{~min}$. This blocks any nonspecific protein binding sites and minimizes nonspecific antibody binding.

3. Incubate with primary antibody, diluted at usual working concentration in PBSBSA (30 min to $1 \mathrm{~h}$ or usual time).

4. Rinse with PBS-BSA (3 times for 1 min).

5. Incubate with Nanogold reagent diluted $1 / 40$ to $1 / 200$ in PBS-BSA with $1 \%$ normal serum from the same species as the Nanogold reagent, for $10 \mathrm{~min}$ to 1 $h$ at room temperature.

6. Rinse with PBS-BSA (3 times for 1 $\mathrm{min}$ ), then PBS (3 times for $1 \mathrm{~min}$ ).

7. Postfix with $1 \%$ glutaraldehyde in PBS (10 min).

8. Rinse in deionized water ( 2 times for 5 min).

9. Silver enhance (see appropriate chapter).

10. Dehydrate and embed according to usual procedure.

11. Stain (uranyl acetate, lead citrate, or other positive staining reagent) as usual before examination.

Protocol 4. Nanogold Labeling for TEM Postembedding

\section{Staining Procedure 1}

1. Prepare sections on plastic or carboncoated nickel grid. Float on a drop of water for 5 to $10 \mathrm{~min}$.

2. Incubate with $1 \%$ solution of PBSBSA buffer at $\mathrm{pH} 7.4$ for $5 \mathrm{~min}$ to block nonspecific protein binding sites.

3. Incubate with primary antibody, diluted at usual working concentration in PBS-BSA (1 h or usual time).

4. Rinse with PBS-BSA (3 times for 1 min).

5. Incubate with Nanogold reagent diluted $1 / 40$ to $1 / 200$ in PBS-BSA with $1 \%$ 
normal serum from the same species as the Nanogold reagent, for $10 \mathrm{~min}$ to 1 h at room temperature.

6. Rinse with PBS (3 times for $1 \mathrm{~min}$ ).

7. Postfix with $1 \%$ glutardialdehyde in PBS at room temperature ( $3 \mathrm{~min}$ ).

8. Rinse in deionized water for (2 times for $5 \mathrm{~min}$ ).

9. Silver enhance (see appropriate chapter in this volume).

10. If desired, contrast sections with uranyl acetate and/or lead citrate before examination.

Note: Thin sections mounted on grids are floated on drops of solutions on parafilm or in well plates. Hydrophobic resins usually require pre-etching. $\mathrm{AMG}$ silver enhancement renders the small Nanogold particles more easily visible. This is usually recommended and especially if stains such as uranyl acetate or lead citrate are applied. Silver enhancement should be completed before these stains are applied.

\section{Staining Procedure 2}

This more specific procedure for postembedding labeling is taken from Krenács and Dux: ${ }^{20}$

1. Fix tissue in $4 \%$ formaldehyde with $0.1 \%$ glutaraldehyde.

2. Embed from $96 \%$ ethanol in LR White (Electron Microscopy Sciences, Fort Washington, PA, USA) according to manufacturer's instructions.

3. Section.

4. Incubate section with primary antibody (diluted in $\mathrm{PBS}++$ overnight at $4^{\circ} \mathrm{C}$ ) and wash with buffer.

5. Incubate with Nanogold-Fab' for 40 min (diluted $1: 30$ in PBS ++ ) and wash.

6. Postfix in $1 \%$ glutardialdehyde PBS for $5 \mathrm{~min}$.
7. Wash 6 times for $1 \mathrm{~min}$ each with bidistilled water.

8. Silver enhance on drops of developer for 2 to $4 \mathrm{~min}$.

9. Wash and counterstain with uranyl acetate and lead citrate for 5 min each.

Protocol 5. Double Labeling for EM:

Nanogold and $10 \mathrm{~nm}$ Colloidal Gold (32)

\section{Staining Procedure}

1. Incubate cryosections (or standard sections) overnight in PBS with 1\% nonfat dry milk.

2. Incubate sections with primary antibody (usually diluted approximately $1: 50$ ) in PBS $^{*}$ containing $0.02 \%$ sodium azide for $3 \mathrm{~h}$ at $22^{\circ} \mathrm{C}$.

3. Wash in 5 changes of PBS.

4. Incubate with secondary NanogoldFab' $^{\prime}$ (diluted 1:50 or 1:100 in PBS $^{*}$ ) for $2 \mathrm{~h}$ at $22^{\circ} \mathrm{C}$.

5. Wash 5 times with PBS.

6. Wash 5 times in $50 \mathrm{mmol} / \mathrm{L}$ MES [1(N-morpholino)-ethanesulfonate] buffer, pH 6.1.

7. Silver enhance sections and wash with water, then PBS.

8. Incubate with primary to second antigen to be localized (diluted in PBS* containing $0.02 \%$ sodium azide) for 3 $\mathrm{h}$ at $22^{\circ} \mathrm{C}$.

9. Wash in 5 changes of PBS.

10. Incubate with $10 \mathrm{~nm}$ colloidal gold secondary antibody diluted in $\mathrm{PBS}^{*}$ for $2 \mathrm{~h}$ at $22^{\circ} \mathrm{C}$.

11. Wash and poststain as usual.

\section{Protocol 6. Negative Stains With} Nanogold: EM

Because the $1.4 \mathrm{~nm}$ Nanogold particles are so small, overstaining with $\mathrm{OsO} 4$, 
Microscopic Uses of Nanogold ${ }^{\circledR}$

uranyl acetate, or lead citrate may tend to obscure direct visualization of individual (unenhanced) Nanogold particles. Three recommendations for improved visibility of Nanogold are: (1) use of reduced amounts or concentrations of usual stains; (2) use of lower atomic number stains such as NanoVan, a vanadium based stain; or (3) enhancement of Nanogold with AMG silver developers prior to staining.

\section{Staining Procedure}

1. Wash carbon film on EM grid several times with buffer, wicking with filter paper; final time leave $5 \mu \mathrm{L}$.

2. Inject $5 \mu \mathrm{L}$ of sample (containing, e.g., isolated molecules in solution labeled with Nanogold) into drop on grid.

3. Wait 1 min for attachment of protein molecules to carbon film on grid.

4. Wash 6 times total with buffer, then water (if compatible), wicking off excess.

5. Wash 3 times with NanoVan.

6. After $1 \mathrm{~min}$, wick to thin layer of fluid and allow to air dry.

\section{Protocol 7. Nanogold Labeling Using Monomaleimido-Nanogold: Labeling Fab' Fragments with Nanogold}

If $\mathrm{F}\left(\mathrm{ab} \mathrm{b}_{2}\right)_{2}$ fragments are available, they should be used for this purpose. If these are not available, they should be prepared from $\operatorname{IgG}$ molecules by digestion with ficin or pepsin, 23,26 It should be noted that IgG molecules from different host animals vary slightly in structure, and therefore will differ in the ease with which they are digested in this way. The procedure given below has been found to be effective in the preparation of $\mathrm{F}\left(\mathrm{ab}^{\prime}\right)_{2}$ fragments from IgG developed in goat. Pepsin becomes more active as the $\mathrm{pH}$ is lowered; at $\mathrm{pH} 7$ it is inactivat- ed. Some monoclonal antibody subclasses may be unsuitable for this process (for example, IgG3). A comprehensive review has been published which describes the use of pepsin digestion to prepare $F\left(a b^{\prime}\right)_{2}$ fragments from mouse monoclonal IgG molecules and details which classes may be digested in this manner. ${ }^{26}$

Note: Procedures given for labeling with Monomaleimido-Nanogold refer to labeling with $30 \mathrm{nmol}$ of the Nanogold labeling reagent. If you are using the smaller $6 \mathrm{nmol}$ size, quantities should be reduced by a factor of five.

\section{Labeling Procedure}

1. Dissolve IgG in $0.1 \mathrm{~mol} / \mathrm{L}$ sodium citrate buffer at $\mathrm{pH} 4.5$; add a solution of pepsin in $0.5 \mathrm{~mL}$ of the same buffer. Use an amount of pepsin equal to $2 \%$ of the mass of $\operatorname{IgG}$. Incubate at $37^{\circ} \mathrm{C}$ for $20 \mathrm{~h}$ using a water bath or incubator.

2. Isolate the $\mathrm{F}\left(\mathrm{ab}^{\prime}\right)_{2}$ fragments by highperformance liquid chromatography (HPLC), using a column such as Amersham Pharmacia Biotech Superose $\mathrm{e}^{\mathrm{TM}} 6$ or 12, TSK 3000, or Toyosoda MacMod GF-250 (which have wide molecular weight fractionation ranges), or a superfine exclusion gel such as Amicon GCL300 (which excludes compounds with molecular weights above 60000). Dialysis does not provide acceptable purification in this application. Elute with 0.02 $\mathrm{mol} / \mathrm{L}$ sodium phosphate at $\mathrm{pH} 7.4$ with $150 \mathrm{mmol} / \mathrm{L}$ sodium chloride and $1 \mathrm{mmol} / \mathrm{L}$ EDTA. The $\mathrm{F}\left(\mathrm{ab}^{\prime}\right)_{2}$ fragments will elute in the void volume if a GCL-300 column is used as the first band. Combine the fractions containing $\mathrm{F}\left(\mathrm{ab}^{\prime}\right)_{2}$ fragments and calculate the amount using the optical density. Concentrate to $0.5 \mathrm{~mL}$ or less using membrane centrifugation. 
3. Dilute the antibody in $0.1 \mathrm{~mol} / \mathrm{L}$ sodium phosphate buffer, $\mathrm{pH}$ 6.0, containing $5 \mathrm{mmol} / \mathrm{L}$ EDTA (make up to 1 $\mathrm{mL}$ ), and dissolve mercaptoethylamine hydrochloride (MEA: $6 \mathrm{mg}$ ) in this solution. Incubate at room temperature for $1 \mathrm{~h}$. This step reduces the hinge region cysteine bond(s), separating the $\mathrm{F}\left(\mathrm{ab}^{\prime}\right)_{2}$ into two $\mathrm{Fab}^{\prime}$ molecules.

4. Isolate Fab' fragments by gel filtration chromatography. Use a desalting gel, such as Amicon GH-25, which has an exclusion cutoff at molecular weight 3000. As the eluent, use $0.02 \mathrm{~mol} / \mathrm{L}$ sodium phosphate at $\mathrm{pH} 6.5$, with 150 $\mathrm{mmol} / \mathrm{L}$ sodium chloride and $1 \mathrm{mmol} / \mathrm{L}$ EDTA. The reduced antibody will be eluted in the void volume as the first sharp peak in the trace. Combine the fractions containing reduced artibody; the total amount of antibody should be calculated from the optical density (usually for $\mathrm{Fab}^{\prime}, \mathrm{E}^{1 \%}$ at $280 \mathrm{~nm}=15.3$; concentration in $\mathrm{mg} / \mathrm{mL}=\mathrm{OD}_{280 \mathrm{~nm}} \times 10 /$ $\left.E^{1 \%}=O_{280 \mathrm{~nm}} \times 0.65\right)$.

5. Dissolve the Nanogold reagent in 0.1 $\mathrm{mL}$ isopropanol or DMSO (dimethyl sulfoxide), then dilute to $1 \mathrm{~mL}$ with deionized water. Sufficient reagent is supplied to label $0.2 \mathrm{mg}$ of Fab'. If you are using a smaller amount, use a proportionately smaller amount of the Nanogold reagent. Once activated, Nanogold is reconstituted with water, and it should be used immediately. The maleimide group is hydrolyzed in aqueous solution.

6. Add the activated Nanogold solution to the Fab' fragments, and either:

a. Incubate at room temperature for 1 $h$; or

b. Incubate for 12 to $18 \mathrm{~h}$ at $4^{\circ} \mathrm{C}$.

7. Separate the unbound gold particles from the antibody conjugates using gel cxclusion chromatography. The Nano- gold conjugate may be effectively isolated using a medium such as Superose 6 or 12 (which fractionate a wide range of molecular weights) or Amicon GCL-90 (which excludes molecules of mass 30000 or greater). Concentrate the reaction mixture to a suitably small volume using membrane centrifugation (e.g., Centricon-30 system). Elute with $0.02 \mathrm{~mol} / \mathrm{L}$ sodium phosphate at $\mathrm{pH}$ 7.4 with $150 \mathrm{mmol} / \mathrm{L}$ sodium chloride. The first, faintly colored peak is the conjugate, while the second, darker band is unbound Nanogold particles. For even higher purity, repeat the this process one time.

The extent of labeling may be determined from the UV visible spectrum of the conjugate. ${ }^{11}$ Nanogold has an extinction coefficient at $280 \mathrm{~nm}$ of $2.25 \times 10^{5}$ and at $420 \mathrm{~nm}$ of $1.12 \times 10^{5}$. This means that for Fab' labeled 100\% (one Nanogold particle to one Fab' molecule), the ratio of optical densities at 280 and $420 \mathrm{~nm}$ is close to 2.7 (extinction coefficient at $280 \mathrm{~nm}$ for Fab' is $\left.7.5 \times 10^{4}\right)$.

Nanogold conjugates should be stored in $0.02 \mathrm{~mol} / \mathrm{L}$ sodium phosphate buffer with $150 \mathrm{mmol} / \mathrm{L}$ sodium chloride. If they are to be stored longer than three days, add $0.1 \% \mathrm{BSA}$ and $0.05 \%$ sodium azide to prevent bacterial contamination and to prevent the protein from adhering to the surfaces of the storage vessel.

Protocol 8. Labeling IgG Molecules with Monomaleimido-Nanogold

IgG molecules contain disulfide bonds which connect the chains in the hinge region. These are reduced with a mild reducing agent, such as MEA, and then reacted with the Nanogold reagent in buffer solution, either for $1 \mathrm{~h}$ at room temperature or overnight at $4^{\circ} \mathrm{C}$. The coupling reaction should be performed at $\mathrm{pH} 6.5$, since at $\mathrm{pH}$ 
values greater than 7.5 the maleimido group becomes slightly reactive towards primary amines as well as sulfhydryls and may give nonspecific labeling. The reduced antibody must be isolated from the MEA before reaction. This may be achieved by gel filtration, using a gel such as GH-25. The Nanogoldconjugated product may be isolated by gel filtration, using a fine gel such as Superose 6 or 12, Superdex ${ }^{\mathrm{TM}} 75$ (Amersham Pharmacia Biotech), or GCL-90.

\section{Labeling Procedure}

1. Dissolve the antibody (0.6 $\mathrm{mg} \operatorname{IgG})$ in $0.1 \mathrm{~mol} / \mathrm{L}$ sodium phosphate buffer, $\mathrm{pH} 6.0$, containing $5 \mathrm{mmol} / \mathrm{L}$ EDTA $(1 \mathrm{~mL})$, and dissolve MEA (8 mg) in this solution. Incubate at room temperature for $1 \mathrm{~h}$.

2. Isolate reduced antibody by gel filtration chromatography. Use a gel such as GH-25. Dialysis does not provide acceptable purification in this application. As the eluent, use $0.02 \mathrm{~mol} / \mathrm{L}$ sodium phosphate at $\mathrm{pH} 6.5$, with $150 \mathrm{mmol} / \mathrm{L}$ sodium chloride and 1 $\mathrm{mmol} / \mathrm{L}$ EDTA. The reduced antibody will be eluted in the void volume as the first sharp peak in the trace. Combine the fractions containing reduced antibody. The total amount of antibody should be calculated from the optical density (usually for $\mathrm{IgG}, \mathrm{E}^{1 \%}$ at $280 \mathrm{~nm}=14.5$; concentration in $\mathrm{mg} / \mathrm{mL}=\mathrm{OD}_{280 \mathrm{~nm}} \times 10 / \mathrm{E}^{1 \%}=$ $\mathrm{OD}_{280 \mathrm{~nm}} \times 0.69$ ).

3. Dissolve the Nanogold reagent in 0.1 $\mathrm{mL}$ isopropanol or DMSO, then dilute to $1 \mathrm{~mL}$ with deionized water. Sufficient reagent is supplied to label $0.6 \mathrm{mg}$ of $\operatorname{IgG}$. If you are using a smaller amount, use a proportionately smaller amount of the Nanogold reagent. Once activated Nanogold is reconstituted with water, it should be used immediately. The maleimide group is hydrolyzed in aqueous solution.
4. Add the activated Nanogold solution to the reduced antibody. Incubate for 12 to $18 \mathrm{~h}$ at $4^{\circ} \mathrm{C}$.

5. Separate the unbound gold particles from the antibody conjugates using gel exclusion chromatography. The Nanogold conjugate may be effectively isolated using a medium such as Superose 6 or 12 or GCL-90. Concentrate the reaction mixture to a suitably small volume using membrane centrifugation (e.g., Centricon-30 system). Elute with $0.02 \mathrm{~mol} / \mathrm{L}$ sodium phosphate at $\mathrm{pH}$ 7.4 with $150 \mathrm{mmol} / \mathrm{L}$ sodium chloride. The first, faintly colored peak is the conjugate, while the second, darker band is unbound Nanogold particles. For even higher purity, repeat this process one time.

The extent of labeling may be determined from the UV visible spectrum of the conjugate. Nanogold has an extinction coefficient at $280 \mathrm{~nm}$ of $2.25 \times 10^{5}$ and at $420 \mathrm{~nm}$ of $1.12 \times 10^{5}$. This means that for IgG labeled $100 \%$ (one Nanogold particle to one $\operatorname{IgG}$ molecule), the ratio of optical densities at 280 and $420 \mathrm{~nm}$ is close to 4.0 (extinction coefficient at $280 \mathrm{~nm}$ for $\mathrm{IgG}$ is $\left.2.2 \times 10^{5}\right)$.

\section{Protocol 9. Labeling other Proteins with} Monomaleimido-Nariogold

Monomaleimido-Nanogold may be used to label any protein with an accessible sulfhydryl group, such as a cysteine residue, in the same manner as described above for antibodies.

In some proteins, the sulfhydryl functionality is in the form of a disulfide group. This must be reduced with a mild reducing agent, such as MEA or DTT, before it can be labeled. If you are unsure of the structure of your protein and have sufficient quantity available, it is recommended that the suitability of the sulfhydryl for labeling be 
determined first; some sulfhydryl sites may be buried within the protein structure, and therefore inaccessible to the Nanogold reagent. The suitability of a particular protein for Nanogold labeling may be determined using ${ }^{14} \mathrm{C}$ iodoacetic acid before gold labeling is tried. Alternatively, sensitive colorimetric procedures exists for sulfhydryl determination, including use of Ellman's reagent [5,5'-dithio-bis-(2-nitrobenzoic acid) (DTNB)], or maleimido-fluorescein.

Sufficient Nanogold reagent is supplied to label $4 \mathrm{nmol}$ of sulfhydryl groups (e.g., $0.4 \mathrm{mg}$ of a 100000 molecular weight compound with one sulfhydryl). Once activated Nanogold is reconstituted with water, it should be used immediately. The maleimide group is hydrolyzed in aqueous solution. The reaction should be performed in the same manner as for antibodies and antibody fragments. For purification and isolation steps, alternative buffers may be substituted for those given. However, the labeling reaction itself should be performed using the buffers and conditions specified.

\section{Labeling Procedure}

1. If the labeling site is in the form of a disulfide group, it may be reduced to the free sulfhydryl with MEA or DTT. Dissolve the protein $(0.6 \mathrm{mg} \mathrm{IgG})$ in $0.1 \mathrm{~mol} / \mathrm{L}$ sodium phosphate buffer, $\mathrm{pH} 6.0$, containing $5 \mathrm{mmol} / \mathrm{L}$ EDTA $(1 \mathrm{~mL})$, and dissolve MEA ( $8 \mathrm{mg} ; 70$ $\mathrm{mmol} / \mathrm{L}$ final) in this solution. Incubate at room temperature for $1 \mathrm{~h}$. Lower amounts of reducing agent (e.g., 10 $\mathrm{mmol} / \mathrm{L}$ final) may be more gentle and adequate for specific proteins.

2. Isolate the reduced protein by gel filtration chromatography. Use a gel, such as $\mathrm{GH}=25$. Dialysis does not provide acceptable purification in this application. As the eluent, use $0.02 \mathrm{~mol} / \mathrm{L}$ sodium phosphate at $\mathrm{pH}$ 6.5, with 150 $\mathrm{mmol} / \mathrm{L}$ sodium chloride and $1 \mathrm{mmol} / \mathrm{L}$
EDTA. The reduced protein will be eluted in the void volume as the first sharp peak in the trace. Combine the fractions containing reduced protein, and the total amount of protein should be calculated from the optical density.

3. Dissolve the Nanogold reagent in $0.1 \mathrm{~mL}$ isopropanol or DMSO, then dilute to 1 $\mathrm{mL}$ with deionized water. Smaller volumes are not recommended since the reagent contains buffers. Sufficient reagent is supplied to label $0.2 \mathrm{mg}$ of $\mathrm{Fab}^{\prime}$. If you are using a smaller amount, use a proportionately smaller amount of the Nanogold reagent. Once activated Nanogold is reconstituted with water, it should be used immediately. The maleimide group is hydrolyzed in aqueous solution.

4. Add the activated Nanogold solution to the reduced protein. Incubate for 12 to $18 \mathrm{~h}$ at $4^{\circ} \mathrm{C}$.

5. Separate the unbound gold particles from the protein conjugates using gel exclusion chromatography. The Nanogold conjugate may be effectively isolated using a medium such as Superose 6 or 12 or GCL-90. Concentrate the reaction mixture to a suitably small volume using membrane centrifugation (e.g., Centricon-30 system). Elute with $0.02 \mathrm{~mol} / \mathrm{L}$ sodium phosphate at $\mathrm{pH}$ 7.4 with $150 \mathrm{mmol} / \mathrm{L}$ sodium chloride. The first, faintly colored peak is the conjugate, while the second, darker band is unbound Nanogold particles. For even higher purity, repeat this process one time.

Caution: Nanogold particles degrade upon exposure to thiols such as BME or DTT.

Protocol 10. Labeling Proteins (MW 15000 or Greater) with Mono-NHSNanogold

Mono-NHS-Nanogold (here the sulfo 
form is used for greater water solubility) is a reagent that is specific for labeling primary amines, including lysines and the alphaamino terminus of proteins. For most proteins, no pretreatment is necessary, since amines will be present. The procedure described below is suggested for labeling larger proteins (MW 15,000 or greater); these are significantly larger than the Nanogold particle (molecular weight approximately 15,000) and may be separated from excess unbound gold by gel exclusion chromatography. The protein is reacted with the Nanogold in buffer solution at $\mathrm{pH} 7.5$ to 8.0 , either for $1 \mathrm{~h}$ at room temperature or overnight at $4^{\circ} \mathrm{C}$. The $\mathrm{pH}$ should be near 7.5 after mixing. The Nanogold-conjugated product may be isolated by gel filtration, using a fine gel such as Superose 6 or 12, Superdex 75, or GCL-90. The recommended procedure is given below:

Note: The procedures given for the use of mono-sulfo-NHS-Nanogold refers to the larger $30 \mathrm{nmol}$ size. If you are using the smaller $6 \mathrm{nmol}$ size, quantities should be reduced by a factor of five.

\section{Labeling Procedure}

1. Dissolve the protein in $0.02 \mathrm{~mol} / \mathrm{L}$ 4,(2-hydroxyethyl)-1-piperazineethanesulfonic acid (HEPES) buffer, adjusted to $\mathrm{pH} 7.5$ with sodium hydroxide. Do not use Tris, as it contains reactive amines that will compete with the protein amines for Nanogold labeling.

2. Dissolve the mono-sulfo-NHS-Nanogold reagent in $1 \mathrm{~mL}$ deionized water. Sufficient reagent is supplied to label 6 nmol of amine sites; if you are using a smaller amount, use a proportionately smaller amount of the Nanogold reagent. Once activated Nanogold is reconstituted with water, it should be used immediately. The succinimide ester is hydrolyzed in aqueous solution.

3. Add the activated Nanogold solution to the dissolved protein. Incubate for either $1 \mathrm{~h}$ at room temperature or 12 to $18 \mathrm{~h}$ at $4^{\circ} \mathrm{C}$.

4. Separate the unbound gold particles from the antibody conjugates using gel exclusion chromatography. Filter the mixture before concentration or before injection on the column to remove suspended solids. The Nanogold conjugate may be effectively isolated by HPLC using a gel such as Superose 6 or 12 or GCL-90. Concentrate the reaction mixture to a suitably small volume using membrane centrifugation (e.g., Centricon-30 system). Elute with 0.02 $\mathrm{mol} / \mathrm{L}$ sodium phosphate at $\mathrm{pH} 7.4$ with $150 \mathrm{mmol} / \mathrm{L}$ sodium chloride. The first, pale yellow peak or shoulder is the conjugate, while the second, darker band is unbound Nanogold particles. For even higher purity, repeat this process one more time.

The extent of labeling may be calculated from the UV visible spectrum of the conjugate. Mono-NHS-Nanogold has extinction coefficients at $280 \mathrm{~nm}$ of $2.3 \times 10^{5}$, and at $420 \mathrm{~nm}$ of $1.1 \times 10^{5}$.

\section{Protocol 11. Labeling Peptides (MW 6000 or Less) with Mono-NHS-Nanogold}

The procedure described below is suggested for labeling smaller peptides (MW 6000 or less); these are significantly smaller than the Nanogold particle (molecular weight approximately 15,000). In this case, separation of excess unreacted peptide from gold-peptide conjugates is usually easier than separating conjugates from unbound gold, and therefore, it is advisable to use an excess of the peptide to be labeled. The protein is reacted with the Nanogold in buffer solution at $\mathrm{pH} 7.5$ to 
8.0 , either for $\mathrm{l} h$ at room temperature or overnight at $4^{\circ} \mathrm{C}$. The $\mathrm{pH}$ should be near 8.0 after mixing. The Nanogold conjugated product may be isolated by gel filtration, using gel which can separate compounds of MW 15,000 and below, such as Superose 12, Superdex 75 or Superdex Peptide, and Bio-Gel P10 or P6 (Bio-Rad). Conjugates of very small peptides (MW 2000 or less) may be separated using a desalting gel such as GH25. Separation may also be achieved by membrane filtration using a microconcentrator such as Centricon-10 (which retains compounds with MW 10,000 and over). Repeated concentrations are necessary to remove all the unbound peptide.

\section{Labeling Procedure}

1. Dissolve the peptide in $0.02 \mathrm{~mol} / \mathrm{L}$ HEPES buffer, adjusted to $\mathrm{pH} 7.5$ with dilute sodium hydroxide ( $1 \mathrm{~mL}$ ).

2. Dissolve the mono-sulfo-NHS-Nanogold reagent in $1 \mathrm{~mL}$ deionized water. $30 \mathrm{nmol}$ of reagent is supplied. Use a 5 to 20-fold excess of the peptide to be labeled. Once activated Nanogold is reconstituted with water, it should be used immediately. The succinimide ester is hydrolyzed in aqueous solution.

3. Add the activated Nanogold solution to the dissolved protein. Incubate for either $1 \mathrm{~h}$ at room temperature or 12 to $18 \mathrm{~h}$ at $4^{\circ} \mathrm{C}$.

4. Separate the gold-peptide conjugates from excess unbound peptide using gel exclusion chromatography. Filter the mixture (e.g., through $0.2-\mu \mathrm{m}$ cellulose acetate spin filter) before concentration or before injection on the column to remove suspended solids. The Nanogold conjugate may be effectively isolated by HPLC using a gel such as Superdex 75 , Superdex Peptide, Bio-Gel P10 or P6
(MW of Nanogold is near 15,000). Concentrate the reaction mixture to a suitably small volume using membrane centrifugation (e.g., Centricon-10 system). Elute with $0.02 \mathrm{~mol} / \mathrm{L}$ sodium phosphate at $\mathrm{pH} 7.4$ with $150 \mathrm{mmol} / \mathrm{L}$ sodium chloride. The first, pale yellowbrown peak or shoulder is the conjugate, while the second, colorless band is excess peptide. For even higher purity, repeat this process one more time.

If the extinction coefficient of the peptide is known, the labeling may be calculated. Sulfo-succinimido-Nanogold has extinction coefficients at $280 \mathrm{~nm}$ of $2.3 \times$ $10^{5}$ and at $420 \mathrm{~nm}$ of $1.1 \times 10^{5}$. However, smaller peptides often have much lower extinction coefficients, which may lead to inaccuracies in calculations.

Note: Proteins with MW close to that of the Nanogold particle $(15,000)$ may be labeled using NHS-Nanogold, but the products cannot be separated by size exclusion chromatography. Other chromatographic techniques, such as reverse-phase, hydrophobic interaction, or ion exchange chromatography may be used. Nanogold is more hydrophobic than most proteins and elutes differently. A Nanogold-peptide conjugate has intermediate characteristics.

\section{PROTOCOLS FOR LABELING LIPOSOMES WITH DPPE- NANOGOLD}

DPPE-Nanogold consists of the $1.4 \mathrm{~nm}$ Nanogold particle covalently linked to a single molecule of dipalmitoyl phosphatidyl ethanolamine. DPPE-Nanogold is hydrophobic and can insert into organic phases in systems such as micelles and liposomes. It is soluble in methanol and in methanol-trichlroromethane and methanol-dichloromethane mixtures. Extinc- 
tion coefficients at specific wavelengths are given below for methanol solution:

$\begin{array}{ll}\text { Wavelength }(\mathrm{nm}): & \text { Extinction } \\ 280 & \text { Coefficient } \mathrm{t}^{\mathrm{a}} \\ 420 & 2.25 \times 10^{5} \\ & 1.12 \times 10^{5}\end{array}$

a Measured for $5 \times 10^{-6} \mathrm{~mol} / \mathrm{L}$ solution in methanol.

As is common with many other Nanogold procedures, visualization of the gold is greatly enhanced in the EM by using AMG silver or gold enhancement. LM applications generally require such enhancement.

Protocol 12. Forming Heavily GoldLabeled Liposomes and Micelles

\section{Labeling Procedure}

1. Dissolve Nanogold-DPPE in methanol, transfer (e.g., $0.5 \mathrm{nmol}$ ) to $1.5-\mathrm{mL}$ polyethylene Eppendorf tube.

2. Evaporate solvent.

3. Add $0.5 \mathrm{~mL}$ water.

4. Sonicate with a microtip unit for 10 to $15 \mathrm{sec}$ (e.g., using Dismembranator 550 [Fisher Scientific, Pittsburgh, PA, USA] with microtip; power level set at 3). Ranges of $5 \mathrm{sec}$ to $10 \mathrm{~min}$ may also be used, but for longer times, a duty cycle should be used to prevent heating (e.g., $20 \mathrm{sec}$ on, $40 \mathrm{sec}$ off).

Protocol 13. Forming Liposomes Spiked with Nanogold-DPPE

\section{Labeling Procedure}

1. Dissolve Nanogold-DPPE in methanol.

2. Aliquot an amount of Nanogold-DPPE into a solution of unlabeled lipids normally used for vesicle formation. Incorporation of $0.1 \%$ to $1 \%$ Nanogold-
DPPE with an unlabeled lipid is usually appropriate for preparing Nanogoldlabeled liposomes with the same properties and morphology as those prepared without the gold label. Frequently a 3:1 chloroform:methanol solvent is used for unlabeled lipids, but a 1:1 chloroform:methanol solvent mixture is recommended for better solubility of the Nanogold-DPPE.

3. Add water and sonicate mixture for 15 min or use other standard methods of liposome preparation. A hazy suspension formed at first indicates multilamellar vesicles (MLV); upon further sonication, the suspension becomes transparent, indicating conversion to small unilamellar vesicles (SUVs). Sonication is usually done in a beaker ice bath, or by duty cycle sonication, to avoid heating and degradation of normal lipids.

Protocol 14. Forming Very Large Liposomes $(>0.5 \mu \mathrm{M})$ Spiked with Nanogold-DPPE

\section{Labeling Procedure}

1. Dissolve Nanogold-DPPE in methanol.

2. Mix $1 \mathrm{nmol}$ Nanogold-DPPE with 10 $\mathrm{nmol}$ lecithin in $0.5 \mathrm{~mL}$ of a $1: 4$ solution of methanol:diethyl ether.

3. Inject solution into $0.1 \mathrm{~mL}$ of $75^{\circ} \mathrm{C}$ water using a 25 -gauge needle.

\section{Protocol 15. Direct Viewing of Nanogold} in the EM

For most work, autometallographic silver enhancement is recommended to give a good signal in the EM (see companion chapters in this volume). For particular applications, visualization of the Nanogold directly may be desirable. Generally this 
requires very thin samples and precludes the use of other high $Z$ stains.

Nanogold provides a much improved resolution and smaller probe size over most other gold antibody products. However, because Nanogold is only $1.4 \mathrm{~nm}$ in diameter, it will not only be smaller, but will appear less intense than, for example, a 5 $\mathrm{nm}$ colloidal gold particle. With careful work, however, Nanogold may be seen directly through the binoculars of a standard EM even in 80-nm thin sections. However, achieving the high resolution necessary for this work may require new demands on your equipment and technique. Several suggestions follow:

\section{Procedure}

1. Before you start a project with Nanogold, it is helpful to see it so you know what to look for. Dilute the Nanogold stock 1:5 and apply $4 \mu \mathrm{L}$ to a grid for 1 min. Wick the drop and wash with deionized water 4 times.

2. View Nanogold at $100,000 \times$ magnification with $10 \times$ binoculars for a final magnification of $1,000,000 \times$. Turn the emission up full and adjust the condenser for maximum illumination. Nanogold is not beam sensitive, so will withstand this dose.

3 . The alignment of the microscope should be in order to give $0.3 \mathrm{~nm}$ resolution. Although the scope should be well aligned, you may be able to skip this step if you do step 4 .

4. Objective stigmators must be optimally set at $100,000 \times$. Even if the rest of the microscope optics are not perfectly aligned, adjustment of the objective stigmators may compensate and give the required resolution. You may want to follow your local protocol for this alignment, but since it is important, a brief protocol is given here:
5. At $100,000 \times\left(1 \times 10^{6}\right.$ with binoculars $)$, over focus, under focus, then set the objective lens to in focus. This is where there is the least amount of detail seen.

6. Adjust each objective stigmator to give the least amount of detail in the image.

7. Repeat steps 5 and 6 until the in-focus image contains virtually no contrast, no wormy details, and gives a flat featureless image.

8. Now underfocus slightly, move to a fresh area, and you should see small black dots of $1.4 \mathrm{~nm}$ size. This is the Nanogold. For the 1:5 dilution suggested, there should be about 5 to 10 gold spots on the small viewing screen used with the binoculars. Contrast and visibility of the gold clusters is best at 0.2 to $0.5 \mu \mathrm{m}$ defocus and is much worse at typical defocus values of 1.5 to $2.0 \mu \mathrm{m}$ commonly used for protein molecular imaging.

9. In order to operate at high magnification with high beam current, thin carbon film over fenestrated holey film is recommended. Alternatively, thin carbon or $0.2 \%$ Formvar over a 1000 mesh grid is acceptable. Many plastic supports are unstable under these conditions of high magnification--high beam current, and carbon is therefore preferred. Contrast is best using thinner films and thinner sections.

10. Once you have seen Nanogold, you may now be able to reduce the beam current and obtain better images on film. For direct viewing with the binoculars, reduction in magnification from $1,000,000 \times$ to $50,000 \times$ makes the Nanogold much more difficult to observe and not all of the golds are discernable. At 30,000 $\times(300,000 \times$ with $10 \times$ binoculars) Nanogold particles are not visible. It is recommended to view at 1,000,000 $\mathrm{x}$, with maximum beam current, align the objective stigmators, and then move to a fresh area, reduce 
the beam, and record on film.

11. If the demands of high resolution are too taxing, or your sample has an interfering stain, a very good result may be obtained using silver enhancement to give particles easily seen at lower magnification.

\section{FURTHER TECHNICAL HINTS AND DISCUSSION}

Nanogold has two very distinguishing features from typical colloidal gold. It is small and is covalently linkable to other molecules. These chemical differences lead to a number of important advantages over colloidal gold technology: (1) stability of the covalently bound antibodies is excellent compared to adsorbed antibodies; ${ }^{19}$ (2) penetration is better, reported up to $40 \mu \mathrm{m}$ in tissues, 31 since the gold is smaller and also a Fab' antibody fragment may be used, which is one-third the size of an IgG (Figure 6.5); (3) higher density of antigen labeling is achieved using smaller gold particles; ${ }^{32}$ (4) many other molecules that do not adsorb to colloidal gold may be easily attached to Nanogold, such as peptides, DNA, lipids, etc.; (5) available as a reagent to chemically link to and label a specific site (e.g., a cysteine or lysine residue); (6) uniform size; $^{12}$ and (7) may be run on gels to follow labeling. ${ }^{7}$ Some potential disadvantages are: (1) its small size generally requires AMG silver enhancement; (2) the sizes after silver enhancement are generally more irregular than a colloidal gold prep; and (3) it is more difficult to synthesize Nanogold and couple it to proteins. The disadvantages are usually outweighed by the significant improvement in immunolabeling sensitivity and density generally observed, unique applications now made possible, and the availability of off-theshelf and easy to use Nanogold reagents (Figure 6.6).

Nanogold conjugates are currently commercially available and include secondary

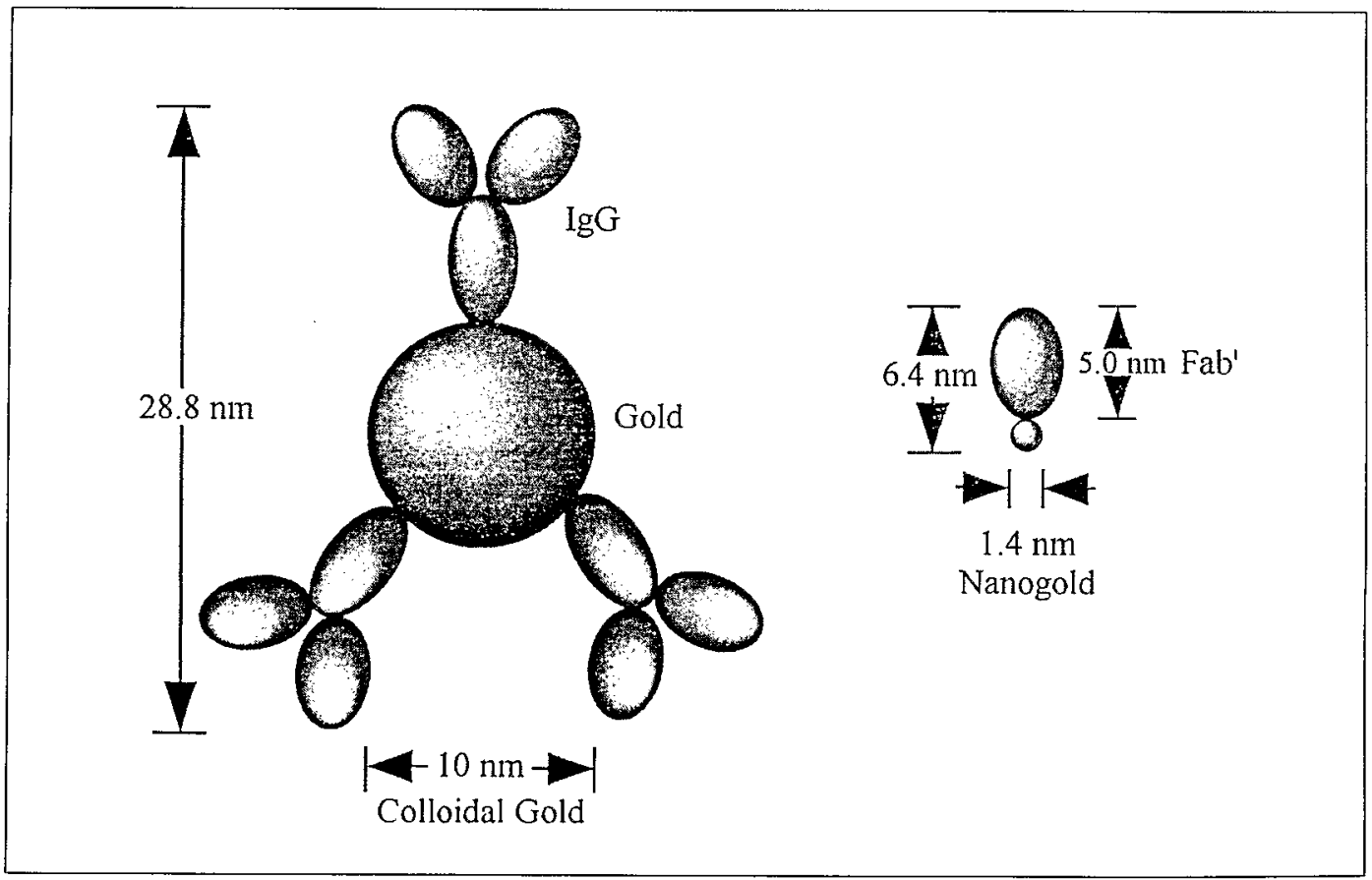

Figure 6.5. Size comparison diagram of colloidal gold IgG probe versus Nanogold-Fab'. The significantly smaller Nanogold probe results in much greater penetration inco tissues and gels. 


\section{Gold and Silver Staining}

antibodies (antimouse, rabbit, goat, etc.), anti-biotin, and Nanogold-streptavidin. Nanogold conjugates are stable to a wide range of buffers and at $\mathrm{pH}$ values from 3.0 to 10.0 , and therefore, they may be used in a similar manner to the usual protocols for other labels. However, specific experience with Nanogold has led to certain protocols that work well, as described above.

Nanogold immunolabeling has now been successfully applied in numerous immunocytochemistry (ICC) studies. 6,20,24,32,34 Frequently, the labeling is much denser than with any colloidal gold probes (Figure 6.7), and in some cases, Nanogold labeling is obtained in experiments where labeling with colloidal gold probes produces no useful signal, especially for sparse or poorly accessible antigens. ${ }^{34}$ It has been pointed out by many investigators that the smaller the gold, the higher the density of labeling. ${ }^{32}$ It has also been shown, however, that "ultrasmall" colloidal golds in the 0.8 to $3 \mathrm{~nm}$ range aggregate

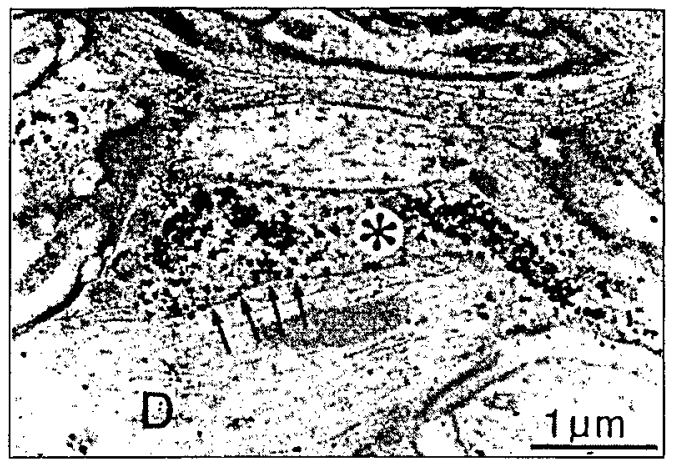

Figure 6.6. Electron micrograph after silver enhancement of Nanogold-Fab' labeling, resulting in convenient, approximately $10 \mathrm{~nm}$, particles. Specimen is from the thoracic spinal cord of the rat and shows GABA-containing terminals (asterisks) forming symmetrical synaptic specializations (arrows) with dendrites (D), with excellent preservation of morphology. Postembedding staining was done using GABA antiserum (Incstar 1:2000, $4^{\circ} \mathrm{C}, 18 \mathrm{~h}$ [Incstar, Stillwater, MN, USA]), Nanogold goat antirabbit Fab' (1:40 room temperature, 90 $\mathrm{min}$ ), and intensified with HQ Silver (Nanoprobes) for 6 min. Tissue was counterstained with lead citrate, and embedding resin was Durcupan (Fluka). (Micrograph provided by $S$ Bacon, Oxford University, Depr. of Pharmacology, Oxford University, Dept. of Pharmacology, Oxford, U.K. and reproduced with permission from Hainfeld, J.E. and F.R. Furuya, 1995. Immunogold-Silver Staining: Principles, Methods, and Applications, CRC Press, Boca Raton, pp. 71-96.)

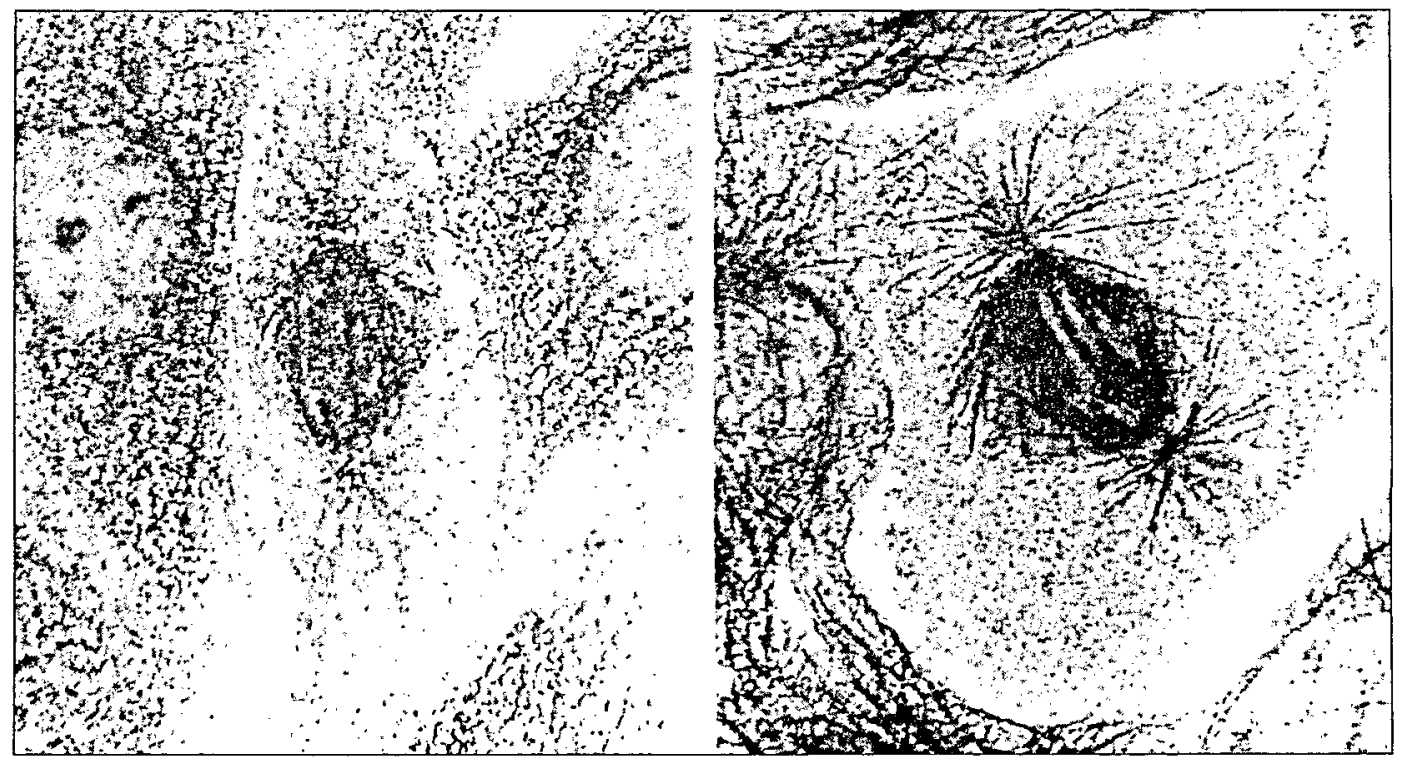

Figure 6.7. Light micrograph comparing ultrasmall colloidal gold labeling (left) with Nanogold-Fab' labeling (right). Spindle microtubules were firse labeled with a mouse antituludin primary followed either with an ultrasmall colloidal gold antimouse probe (left) or Nanogold antimouse Fab' (right). Each sample was treated identically with silver enhancer. (Original magnification, $\times$ 1300.) (Micrographs reproduced with permission from Vandre, D.P. and R.W. Burry, 1992. J. Histochem. Cytochem., 40:1837-1847.) 
and do not appear to perform well compared to the $1.4 \mathrm{~nm}$ Nanogold 9,34 (Figure 6.7).

Immuno-Nanogold labeling has been successfully used both in pre- and postembedding procedures (Figure 6.8). Although
AMG silver enhancement leads to some particle size heterogeneity, it can actually be quite regular (Figure 6.9) and is very useable. The higher density of labeling easily outweighs the slight variation in

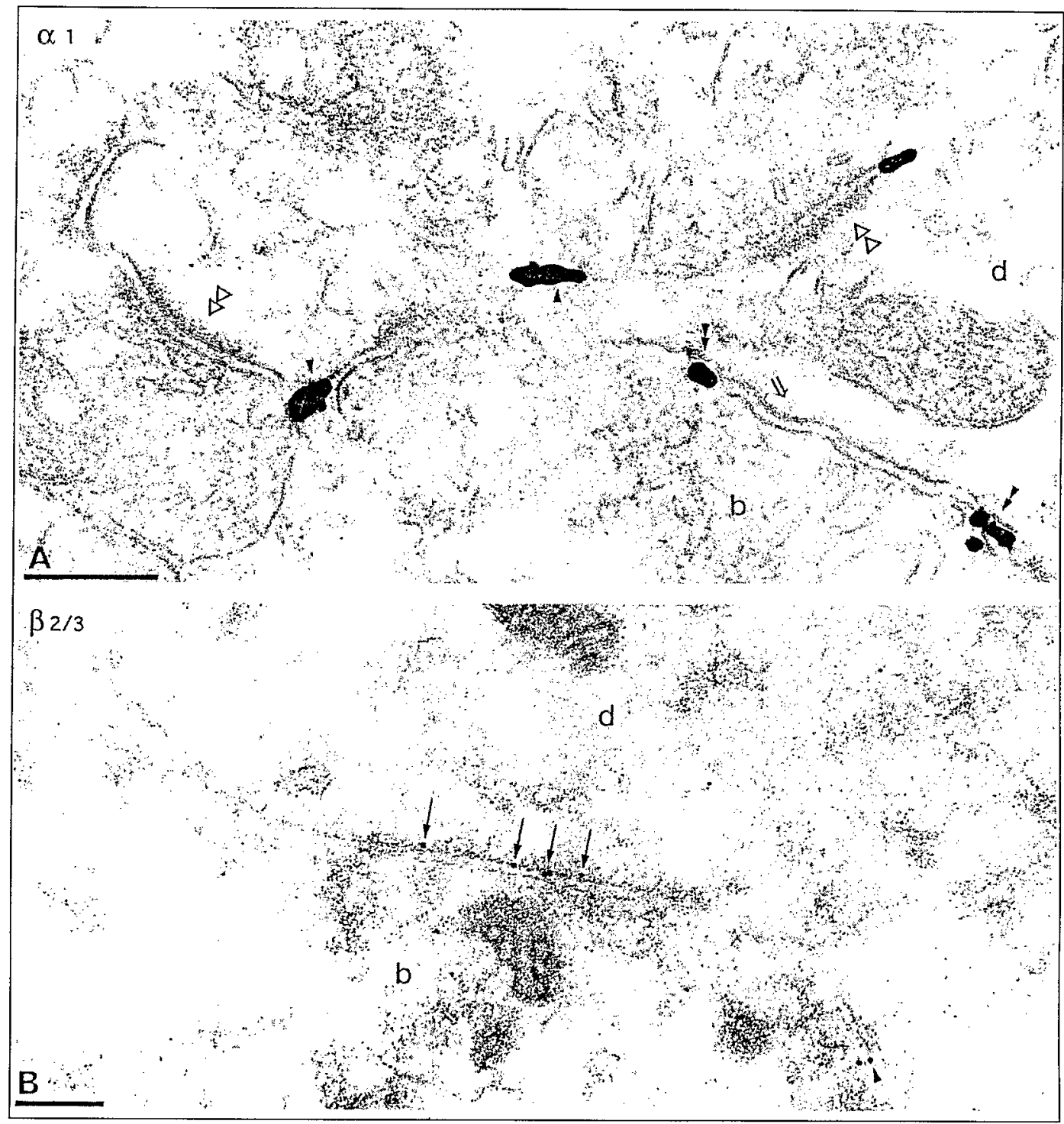

Figure 6.8. Pre-embedding (A) and postembedding (B) with Nanogold. Immunoreactivity for the al $(A)$ and b2/3 (B) subunits in the molccular layer of car cerebellum is demonstrated by either pre-embedding ( $A$, epoxy resin) or postembedding techniques (B, frecze-substituted Lowicryl-embedded). (A) Particles are nor present in synapses (double triangles) including the type 2 synapse (c.g., opcn arrow) berween a presuncd stellate cell terminal (b) and an interneuron dendrite (d). Immunoparticles are often located at the edge of type 2 synapses (double arrowheads) as well as at the extrasynaptic membrane (arrowheads). (B) The postemhedding reaction produces a row of silver-intensified gold particles (arrows) on the postsynaptic plasma membranc at a synaptic junction established by a bouton (b) with a purkinje cell dendrite (d). Some immunoparticles are also present at che extrasynaptic plasma membrane (arrowhead). Bar $=0.2 \mu \mathrm{m}$. (Reproduced with permission from Nusser, Z. et al.,1995. J. Neurosci., 15:2948-2960.) 
enhanced particle size in most applications, compared with using colloidal gold.

Nanogold with AMG silver enhancement may be followed by standard immunolabeling of a different antigen with colloidal gold for double labeling. This was achieved by Takizawa and Robinson. 32 They showed that the labels were readily distinguished and that the silver enhancement was gentle enough to preserve antigenicity when the next immunolabel (a 10 nm colloidal gold) was applied. This is especially useful when one antigen is sparse, since Nanogold usually gives a much stronger signal than colloidal gold immunoconjugates. 27,34

Nanogold is also available as a reagent that can react selectively with thiols or amines (Figure 6.10). ${ }^{10}$ An investigator using these reagents and protocols can prepare primary antibodies or Fab' antibody fragments labeled with Nanogold or covalently couple Nanogold to other molecules. One striking example was the labeling of substance $\mathrm{P}$ (SP), an 11 amino acid peptide, with mono-NHS-Nanogold. 30 Nanogoldlabeled SP was found to behave identically to an 125 I-labeled SP on gels and in tissues. For example, binding of this peptide could be competed out with unlabeled SP or with specific inhibitors. Therefore, the radioactive labeling used in previous studies could be replaced with nontoxic gold. Furthermore, for structural studies, localizations of $\mathrm{SP}$ in spinal column sections could be viewed the same day as opposed to several

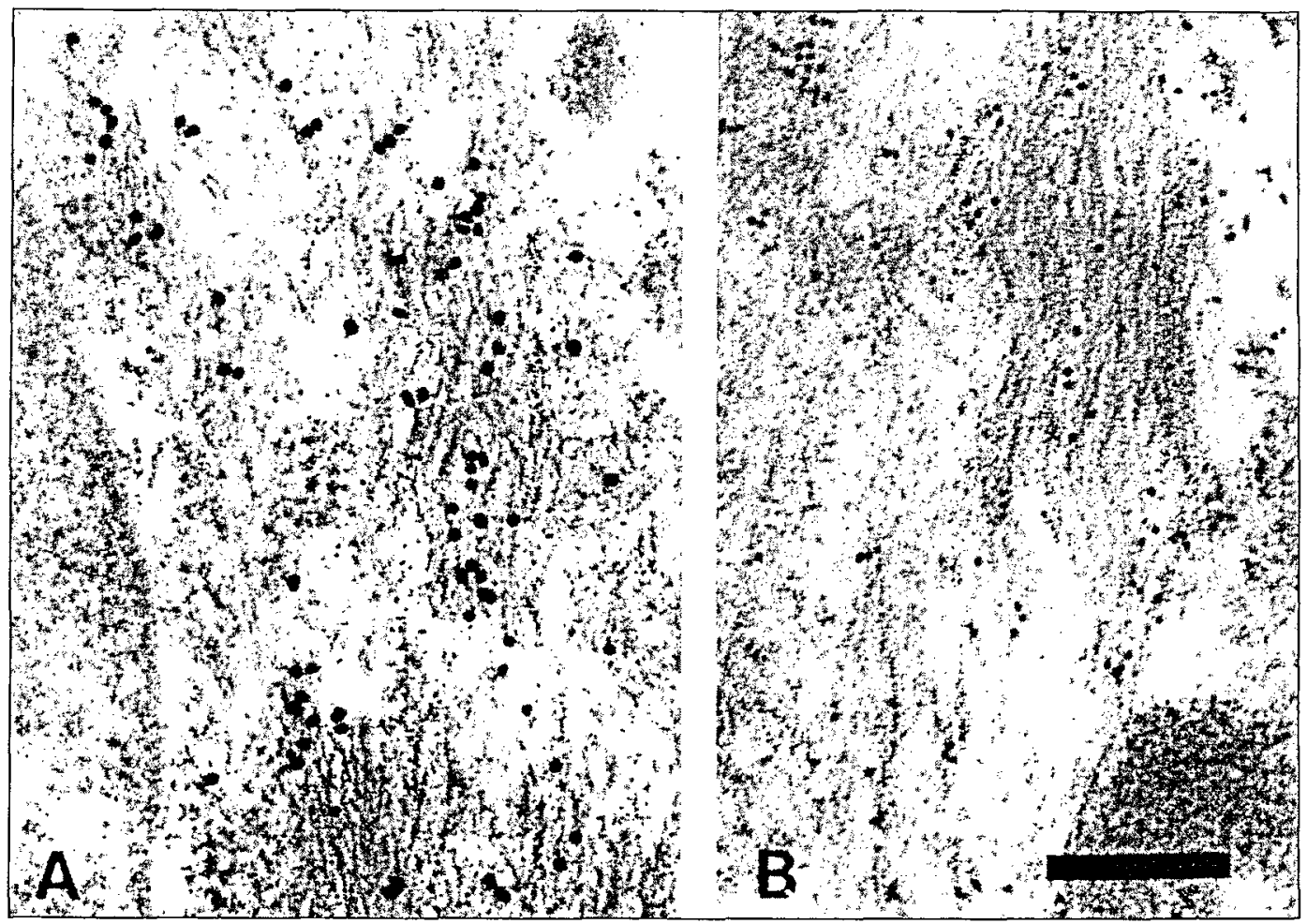

Figure 6.9. Regular sized silver-enhanced Nanogold $(B, 8-10 \mathrm{~nm})$ compared to silver-enhanced $5 \mathrm{~nm}$ colloidal gold (A, $15-20$ $\mathrm{nm}$ ). Ws-keratin was detected with a sccondary $5 \mathrm{~nm}$ gold-IgG goat antimouse IgG (GAM-G5) (A) and Nanogold (B), both followed by a silver enhancement for 3 min. Tissue was a mamnary carcinoma, embedded in Lowicryl $\mathrm{K} 4 \mathrm{M}$ resin. The quite homogeneous particles are about 8 to $10 \mathrm{~nm}$ with Nanogold (B), and 15 to $20 \mathrm{~nm}$ using GAM-G5 (A). Bar $=200 \mathrm{~nm}$. (Reproduced with permission from Krenícs, T. and L. Ḱrenács, 1995, in Immenogold-Siluer Staining: Principles, Methods and Applications, CRC ['ress, Boca Raton, pp. 57-70.) 


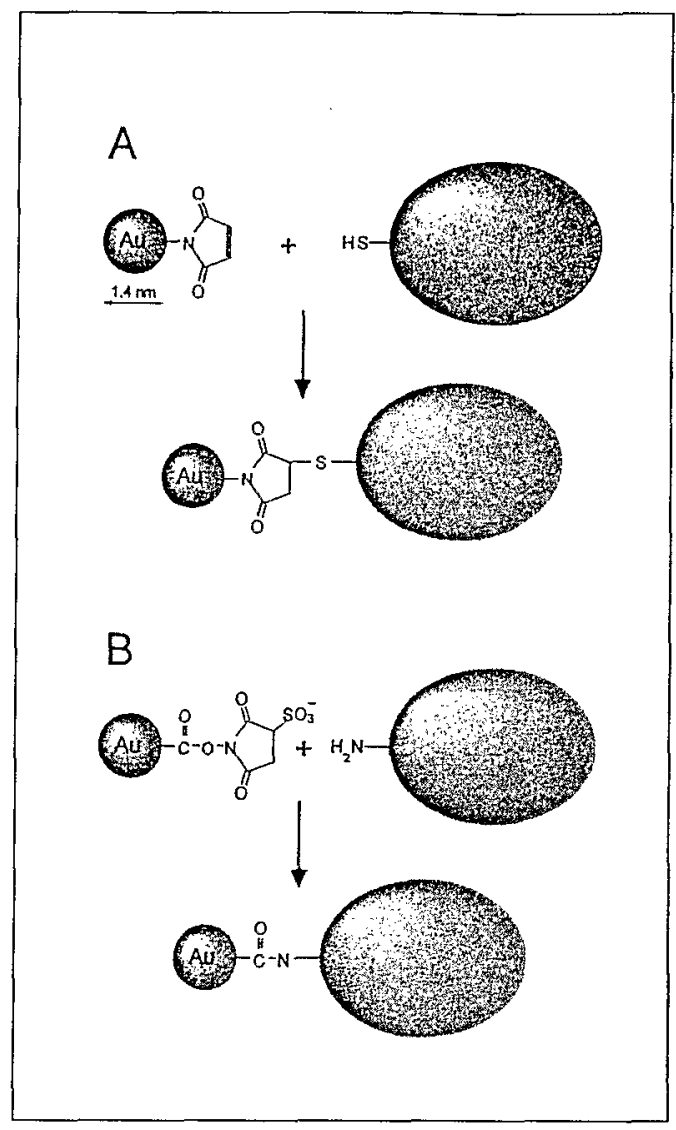

Figure 6.10. Diagram of Nanogold reagents. (A) Monomaleimido-Nanogold has a maleimide group that reacts with free sulfhydryls, and (B) mono-NHS-Nanogold has a sulfoN-hydroxysuccinimide ester that reacts with amines. Both reacrions are very specific and occur rapidly under mild physiological condirions. months of film exposure for the autoradiographic approach previously used.

Another recent example of the use of Nanogold reagents was the labeling of insulin to study the insulin receptor. 22 Nanogold-insulin was found to retain its activity and, when bound to the insulin receptor, was then used to help determine the high resolution structure of this important protein.

The high resolution scanning transmission electron microscope (STEM) is excellent for

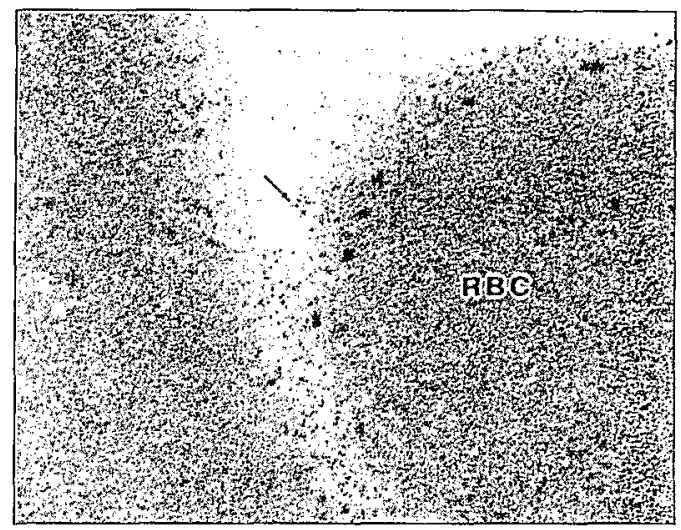

Figure 6.11. TEM brightfield micrograph of red blood cells labeled with Nanogold antihuman red blood cell (RBC)$\mathrm{Fab}^{\prime}$, then fixed, embedded in Lowicryl K4M, and thin sectioned. No additional staining was used, and in this $80-\mathrm{nm}$ section, individual Nanogold parricles are visible (arrow) along the membrane surfaces. Full width $0.18 \mu \mathrm{m}$.

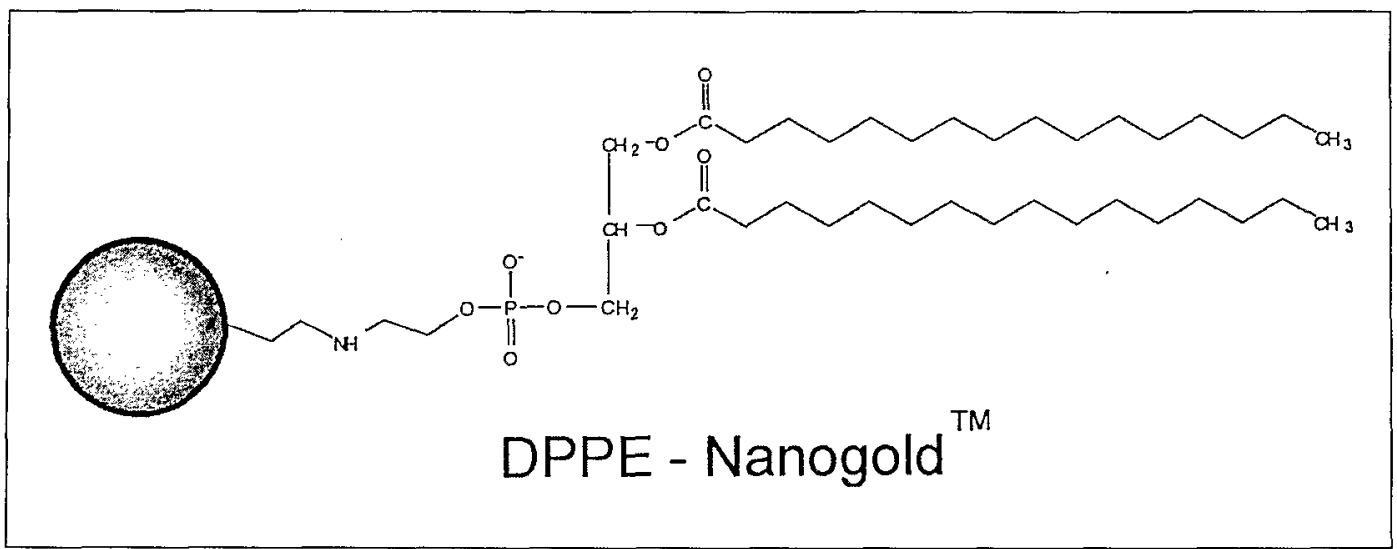

Fïgure 6.12. Nanogold-DPPE schematic diagram, showing covalent attachment of Nanogold to the head group of a 16 carbontailed phospholipid, DPPE. 


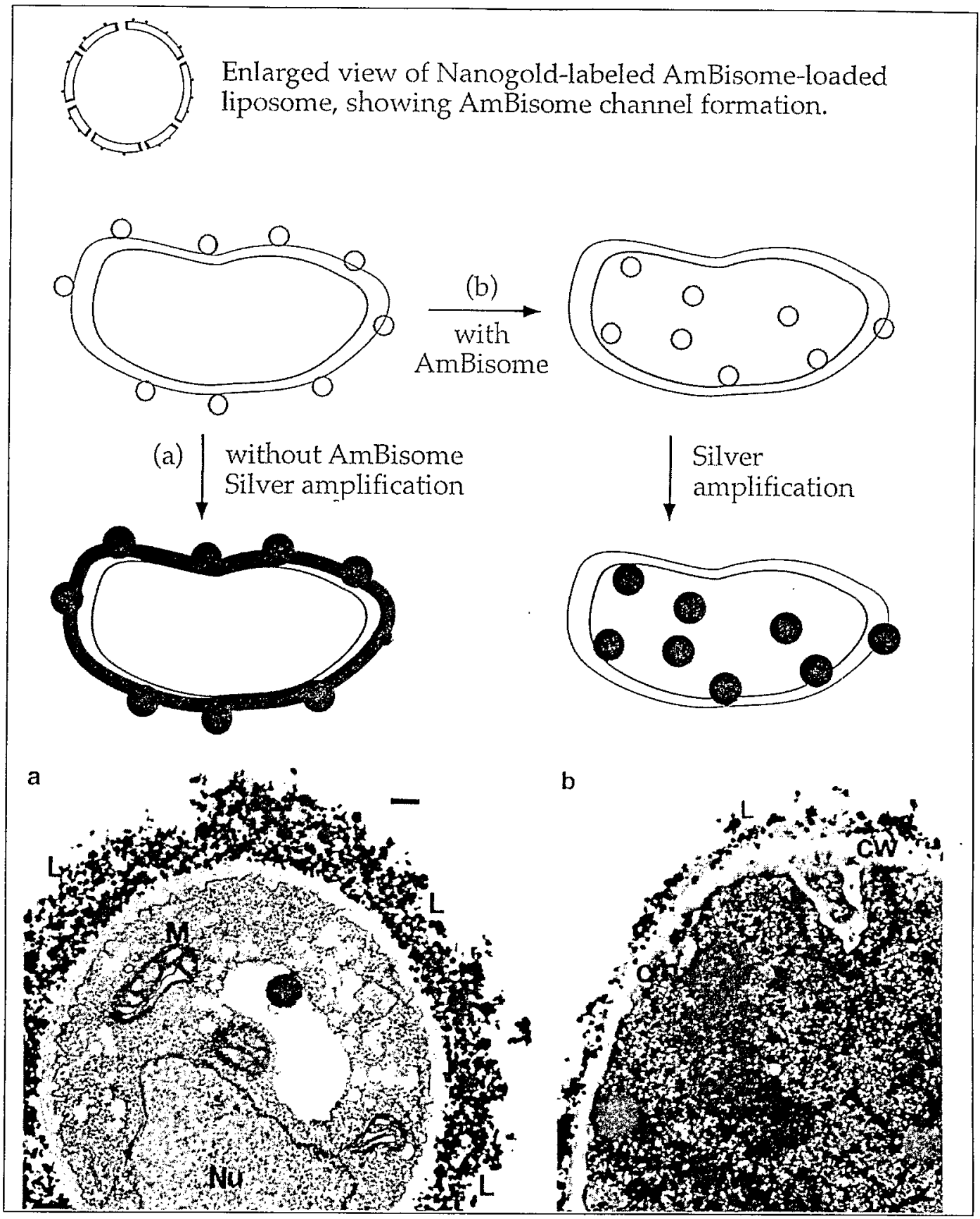

Figure 6.13. Nanogold-DPPE labeling of a drug-delivery liposome. (Top panel) Schematic showing liposome containing the antifungal drug, amphotericin B (AmBisome), and Nanogold-lipid-labelcd. (Middle panel) Schematic of experiments showing targering of liposomes (small circles) to a fungal cell, followed by silver enhancement. If drug was absent (a), liposomes targered the cell, but had no further effect. With drug, (b), the cell wall was penetrated, and drug and lipids entered the cell. Micrographs ar botcom show effect after a 14 -h incubation of liposomes with the fungal cells Aspergillus fumigatas. Without the drug in the liposome, liposomes remained exterior to cells (a); with the drug, dark internal staining was observed (b), indicating breach of cell wall and membrane and entry into cells, cventually resulting in cell death. $\mathrm{Nu}=$ nucleus, $L=$ Nanogold-labcled lipid or liposomes, $M=$ mitochondria, $\mathrm{CW}=$ cell wall, and $\mathrm{CM}=$ cell membrane. $\mathrm{Bar}=200 \mathrm{~nm}$. (Micrographs reproduced with permission from Adler-Moore. J., 1994, Bone Marrow Transplant., 14(Suppl) 5.S3-7.) 
visualizing Nanogold and even undecagold, tetrairidium, and single heavy atoms. ${ }^{29}$ However, microscopes are improving all the time, and smaller and smaller gold particles have become visible with more commonly available instruments. Nanogold is visible by both TEM and scanning electron microscopy (SEM). ${ }^{17}$ In TEM, the specimen must be kept thin, so as not to swamp out the small gold signal. For example, Nanogold has been seen with a Philips 300 (FEI, Hillsboro, OR, USA) in approximately $70 \mathrm{~nm}$ thin sections of cells $\mathrm{s}^{12}$ but without the use of stains (Figure 6.11). It has also been seen routinely in cryoEM work, where unstained molecules are embedded in a thin (approximately 100 $\mathrm{nm}$ ) layer of ice. ${ }^{2}$ For single molecule studies, negative staining has been popular for enhancing the contrast and subunit boundaries, but Nanogold is typically lost in the dense layer of uranyl acetate or lead citrate. However, several lower atomic number stains may be used instead. These stains still enhance the molecular images, but scatter less, and permit visualization of each Nanogold particle. Some stains in this category are methylamine vanadate (NanoVan), ${ }^{7}$ ammonium molybdate, glucose mixed with molybdate, and aurothioglucose-glucose. A protocol for using the vanadate stain is given.

Use of the gold-phospholipid, NanogoldDPPE (Figure 6.12) to visualize liposomes in the EM and LM has now been reported by several groups. ${ }^{14,33}$ Nanogold-DPPE-spiked liposomes have even been used to follow and document liposome-based antifungal drug delivery ${ }^{1}$ (Figure 6.13).

For many applications, autometallography (silver enhancement) is required to visualize the small gold. Protocols for its use with Nanogold are given in companion chapters of this volume.

An in-depth revicw comparing a number of investigators' experiences with Nanogold labeling covering additional pro- tocols and comparison of such things as fixation methods and tissue handling techniques is found in the literature. ${ }^{15}$ Also, applications of new reagents based on the covalently linkable Nanogold are described in another chapter in this volume.

In conclusion, Nanogold molecular and immunolabeling have become important new tools for cell biologists and biomedical researchers and continue to expand the usefulness of gold labeling.

\section{ACKNOWLEDGMENTS}

The authors wish to thank Dr. Martha Simon, Ms. Beth Lin, and Mr. Frank Kito for STEM operation, and Dr. Joseph Wall for helpful discussions. This work was supported by the Office of Biological and Environmental Research of the U.S. Department of Energy under Prime Contract No. DE-AC02-98CH10886 with. Brookhaven National Laboratory, by National Institutes of Health (NIH) Grant No. 2P41 RR01777 and by NIH Small Business Innovation Research Grant Nos. GM49564, and GM56090.

\section{REFERENCES}

1.Adler-Moore, J. 1994. AmBisome targeting to fungal infections. Bone Marrow Transplant. 14(Suppl 5):S3-7.

2.Boisset, N., R. Grassucci, P. Penczek, E. Delain, F. Pochon, J. Frank, and J.N. Lamy. 1992. Three-dimensional reconstruction of a complex of human alpha 2 macroglobulin with monomaleimido Nanogold (Au1.4nm) embedded in ice. J. Struct. Biol. 109:3945.

3.Burry, R.W., D.D. Vandre, and D.M. Hayes. 1992. Silver enhancement of gold antibody probes in preembedding electron microscopic immunocytochemistry. J. Histochem. Cytochem. 40:1849-1856.

4.Danscher, G. and J.O. Norgaard. 1983. Light microscopic visualization of colloidal gold on resin-embedded tissue. J. Histochem. Cytochem. 31:1394-1398.

5.Faulk, W.P. and G.M. Taylor. 1971. An inmunocolloid method for the electron nicroscope. Immunochemistry 8:1081-1083.

6.Gilerovitch, H.G., G.A. Bishop, J.S. King, and R.W. Burry. 1995. The use of electron microscopic 
inmunocytochemistry with silver-enhanced $1.4-\mathrm{nm}$ gold particles to localize GAD in the cerebellar nuclei. J. Histochem. Cytochem. 43:337-343.

7.Gregori, L., J.F. Hainfeld, M.N. Simon, and D. Goldgaber. 1997. Binding of amyloid beta protein to the $20 \mathrm{~S}$ proteasome. J. Biol. Chem. 272:58-62.

8.Hacker, G.W., L. Grimelius, G. Danscher, G. Bernatzky, W. Muss, H. Adam, and J. Thurner. 1988. Silver acetate autometallography: an alternative enhancement technique for immunogold-silver staining (IGSS) and silver amplification of gold, silver, mercury, and zinc tissues. J. Histotechnol. 11:213.

9.Hainfeld, J. 1990. STEM analysis of Janssen Aurooprobe One, p. 954-955. In G. Bailey (Ed.), Proc. XIIth Int. Cong. Elec. Micros. San Francisco Press, San Francisco.

10.Hainfeld, J.F. 1996. Labeling with nanogold and undecagold: techniques and results. Scanning Microsc. Suppl. 10:309-322.

11.Hainfeld, J.F. 1989. Undecagold-antibody method, p. 413-429. In M.A. Hayat (Ed.), In Colloidal Gold: Principles, Methods, and Applications, Vol. 2. Academic Press, San Diego.

12.Hainfeld, J.F. and F.R. Furuya. 1992. A 1.4-nm gold cluster covalently attached to antibodies improves immunolabeling. J. Histochem. Cytochem. 40:177-184.

13.Hainfeld, J.F. and F.R. Furuya. 1995. Silver enhancement of Nanogold and undecagold, p. 71-96. In M.A. Hayat (Ed.), Immunogold-Silver Staining: Principles, Methods and Applications. CRC Press, Boca Raton.

14.Hainfeld, J.F, F.R. Furuya, and R.D. Powell. 1999. Metallosomes. J. Struct. Biol. 127:152-160.

15.Hainfeld, J.F. and R.D. Powell. 1997. Nanogold technology: new frontiers in gold labeling. Cell Vision 4:408-432.

16. Handley, D.A. 1989. Methods for synthesis of colloidal gold p. 13-32. In M.A. Hayar (Ed.), In Colloidal Gold: Principles, Merhods, and Applications, Vol. 1. Academic Press, San Diego.

17.Hermann, R., P. Walther, and M. Muller. 1996. Immunogold labeling in scanning electron microscopy [published erratum appears in Histochem. Cell Biol. 1996 Sep;106(3):356. Histochem. Cell Biol. 106:31-39.

18. Holgate, C.S., P. Jackson, P.N. Cowen, and C.C. Bird. 1983. Immunogold-silver staining: new method of immunostaining with enhanced sensitivity. J. Histochem. Cytochem. 31:938-944.

19.Kramarcy, N.R. and R. Sealock. 1991. Commercial preparations of colloidal gold-antibody complexes frequently contain free active antibody. J. Histochem. Cytochem. 39:37-39.

20.Krenács, T. and L. Dux. 1994. Silver-enhanced immunogold labeling of calcium-ATPase in sarcoplasmic reticulum of skeletal muscle [letter; comment]. ]. Histochem. Cytochem. 42:967-968.

21.Krenács, T. and L. Krenács. 1995. Comparison of embedding media for immunogold-silver staining, $p$. 57-70. In M.A. Hayat (Ed.), Immunogold-Silver
Staining: Principles, Methods, and Applications. CRC Press, Boca Raton.

22.Luo, R.Z., D.R. Beniac, A. Fernandes, C.C. Yip, and F.P. Ottensmeyer. 1999. Quaternary structure of the insulin-insulin receptor complex. Science 285:10771080.

23.Mariani, M., M. Camagna, L. Tarditi, and E. Seccamani. 1991. A new enzymatic method to obtain highyield $F(a b) 2$ suitable for clinical use from mouse IgGl. Mol. Immunol. 28:69-77.

24.Nusser, Z., E. Mulvihill, P. Streit, and P. Somogyi. 1994. Subsynaptic segregation of metabotropic and ionotropic glutamate receptors as revealed by immunogold localization. Neuroscience 61:421-427.

25.Nusser, Z., J.D. Roberts, A. Baude, J.G. Richards, and R. Somogyi. 1995. Relative densities of synaptic and extrasynaptic GABAA receptors on cerebellar granule cells as determined by a quantitative immunogold method. J. Neurosci. 15:2948-2960.

26.Parham, P. 1983. On the fragmentation of monoclonal IgG1, IgG2a, and $\operatorname{IgG} 2 \mathrm{~b}$ from $\mathrm{BALB} / \mathrm{c}$ mice. J. Immunol. 131:2895-2902.

27.Robinson, J.M., T. Takizawa, D.D. Vandre, and R.W. Burry. 1998. Ultrasmall immunogold particles: important probes for immunocytochemistry. Microsc. Res. Tech. 42:13-23.

28.Roth, J., M. Bendayan, and L. Orci. 1978. Ultrastructural localizarion of intracellular antigens by the use of protein A-gold complex. J. Histochem. Cyrochem. 26:1074-1081.

29.Safer, D., J. Hainfeld, J.S. Wall, and J.E. Reardon. 1982. Biospecific labeling wich undecagold: visualization of the biotin-binding site on avidin. Science 218:290-291.

30.Segond von Banchet, G. and B. Heppelmann. 1995. Non-radioacrive localization of substance $P$ binding sites in rat brain and spinal cord using peptides labeled with 1.4-nm gold particles. J. Histochem. Cytochem. 43:821-827.

31.Sun, X.J., L.P. Tolbert, and J.G. Hildebrand. 1995. Using laser scanning confocal microscopy as a guide for electron microscopic study: a simple method for correlation of light and electron microscopy. J. Histochem. Cytochem. 43:329-335.

32.Takizawa, T. and J.M. Robinson. 1994. Use of 1.4$\mathrm{nm}$ immunogold parcicles for immunocytochemistry on ultra-thin cryosections. J. Histochem. Cytochem. 42:1615-1623.

33.Thurston, G., J.W. McLean, M. Rizen, P. Baluk, A. Haskell, T.J. Murphy, D. Hanahan, and D.M. McDonald. 1998. Cationic liposomes target angiogenic endothelial cells in tumors and chronic inflammation in mice. J. Clin. Invest. 101:1401-1413.

34.Vandre, D.D. and R.W. Burry. 1992. Immunoelectron microscopic localization of phosphoproteins associated with the mitotic spindle. J. Histochen. Cytochem. 40:1837-1847. 